\title{
Una aproximación a los problemas de grafismo
}

Diana Peñuela*

\section{JUSTIFICACIÓN}

Con este artículo se pretende hacer una revisión sobre las causas mas comunes de los problemas relacionados con la adquisición de la escritura, que tan frecuentemente se presentan en la población escolar.

Una de las áreas donde se empieza a dilucidar una dificultad que conlleva al fracaso escolar es aquella donde se involucra el proceso de la lectoescritura. En las aulas no son pocos los casos en que los niños comienzan a enfrentar dificultades académicas por una letra ilegible, lenta en su ejecución y por lo tanto no funcional para ejercer y tener éxito en el desempeño de su rol como escolar. Las consecuencias derivadas de esto son muchas: disminuye el nivel de rendimiento académico, conductas de evitación o rechazo ante actividades que involucren la escritura, baja autoestima y los padres y maestros pueden empezar a referir transtornos comportamentales como agresividad, temor y fobia para asistir al colegio, pesadillas, depresión, enuresis, entre otros.

Conceptos: Grafismo, Disgrafía.

\section{EVOLUCIÓN DEL GRAFISMO}

Hasta los tres años de edad cada vez que el niño utiliza una herramienta cualquiera para garabatear lo hace como una forma de actividad lúdica y sin un propósito

\footnotetext{
- Terapeuta Ocupacional egresada de la Escuela Colombiana de Rehabilitación afiliada al Colegio Mayor de Nuestra Señora del Rosario. Con entrenamiento en Integración Sensorial de la Universidad del Sur de California. Docente de la Escuela Colombiana de Rehabilitación.
} 
determinado, en donde la característica principal es la descarga motriz que se ejerce a través de la actividad. A partir de esa edad se inicia una etapa en la que el niño intenta representar diferentes objetos, los cuales por razones madurativas no se aproximan a la realidad per̀o en cambio el niño si puede verbalizar lo que quizo representar. Cuando se cansa de garabatear con una mano pasa la herramienta a la otra indistintamente.

A partir de los cuatro años, por los programas desarrollados en las instituciones educativas, el proceso se intensifica. Se inicia el control grafomotor con el que se va aproximando lo que el niño representa con la realidad. Segú René Zazzo en esta edad el porcentaje de niños que emplean una sola mano para las actividades gráficas es del setenta por ciento (70\%).

A partir de los cinco años se empieza a dar el aprendizaje de la escritura como tal, aunque esto puede variar de acuerdo a las criterios de las instituciones educativas.

Ajuriaguerra identifica varias etapas en este proceso de adquisición y establecimiento de la escritura:

- Fase precaligráfica: entre los cinco y los ocho años. Todavia no existe el control motor suficiente para ejecutar los trazos con precisión. Las letras no tienen un tamaño homogéneo y son generalmente inclinadas.

- Fase caligráfica: Desde los ocho o nueve años hasta la pubertad. Se observa un dominio eficaz sobre la herramienta usada para escribir y la escritura se hace cada vez mas fluida y las formas y tamaños de las letras mas parejas. Hacia los diez años se da una fase de equilibrio y aparente armonía en su evolución.

- Fase poscaligráfica: Se produce una crisis en la escritura por la condición propia de la adolescencia. Esta misma crisis lleva al adolescente a adquirir un estilo propio de escritura influenciado por la rapidez que necesita adquirir en su ejecución para adaptarse a las exigencias del medio.

\section{REQUISITOS PARA LA ESCRITURA}

El aprendizaje de la escritura es un paso muy importante en el aprendizaje del niño razón por la cual se debe presentar en el momento indicado. Si se inicia su enseñanza de forma prematura lo estaremos conduciendo al fracaso ya que todavia no 
cuenta con la maduración previa necesaria. Si por el contrario dejamos pasar el momento oportuno en el que ya el niño está capacitado para este proceso educativo, cada vez se hace mas dificil la recuperación del tiempo perdido. Esto es claramente observable: a un niño de siete años le resulta mucho mas fácil aprender a leer y escribir que a un adulto de treinta o cuarenta años de edad.

En la maduración del individuo existen dos factores decisivos que interfieren y le imprimen de unas características particulares:

- Factor Hereditario.

- Factor Ambiental.

Desde la misma concepción del individuo se empiezan a dar dentro de el una serie de cualidades innatas que le den una carácter especial y particular. De tal manera que viene dotado con una serie de características que se desarrollan en el momento adecuado. Estas características están determinadas por el factor hereditario.

Así mismo si el niño no se desenvuelve en un contexto que le proporcione los estímulos necesarios para desarrollar todo ese potencial con el que nace, ese proceso de desarrollo se va a ver alterado. De aquí se puede deducir que el compendio de herencia y ambiente es el proceso educativo que va estrechamente ligado a la evolución del individuo.

Las condiciones necesarias para dar inicio al proceso del aprendizaje de la escritura podrían resumirse en:

1. Adecuada integración sensorio-motora: En términos generales hacia los seis años de edad el niño está lo suficientemente maduro para iniciar el proceso. Para determinarlo en términos específicos es importante que nos detengamos a contemplar los siguientes aspectos:

- Percepción visual.

- Memoria auditiva y visual para recordar los grafismos.

- Destreza motriz para el agarre del lapicero.

- Coordinación visomotora.

- Control y ajustes posturales.

- Reacciones de equilibrio y enderezamiento.

- Praxias. 
2. Adecuado desarrollo del lenguaje: no se puede trazar una linea divisoria entre el lenguaje verbal y el escrito. Existen muchos casos en donde las dificultades para aprender a escribir no son otra cosa que la prolongación de un problema de lenguaje. Si estamos frente a un niño con dificultades a nivel comprensivo, expresivo o de articulación muy dificilmente lo podremos llevar hacia el aprendizaje de la escritura con éxito. Esta es una razón importante para incluir dentro del equipo interdisciplinario en las instituciones educativas al servicio de fonoaudiología.

En este factor de lenguaje es util identificar el poder de asimilación del niño del lenguaje hablado (comprensión), la unificación del lenguaje oral con el lenguaje del pensamiento lo que implica el conocimiento de vocabulario, y la forma en que articula y pronuncia dicho vocabulario. Aquí es importante tener en cuenta que para la escritura espontánea se necesita que haya una buena introyección del lenguaje.

3. Adecuado desarrollo psicosocial: El desarrollo afectivo alterado va a ser un obstáculo importante en el aprendizaje de la escritura. Las primeras relaciones objetales, su contexto familiar y el llamado "destete emocional" de su entorno familiar son definitivos. Recordemos que la plasticidad cerebral es mayor en los primeros años de vida, por lo tanto si al individuo se le ha brindado la oportunidad de asistir a jardines infantiles a compartir con otros niños y a iniciar todas las actividades preparatorias para el aprendizaje del código lectoescrito tendrá mayores posibilidades de éxito. En esos primeros años el ambiente organizado y enriquecido en estímulos son de vital importancia para el desarrollo y maduración del niño.

Aquí cabe recordar los experimentos del "medio ambiente enriquecido" practicado en animales en los que se ha concluido que:

- Aumenta el peso cerebral.

- Aumentan las conexiones sinápticas.

- Aumenta la actividad metabólica del cerebro.

- Aumenta la velocidad del procesamiento sensorial.

- Aumenta la capacidad de exploración ambiental. 
4. Adecuado desarrollo de la inteligencia: Un bajo cociente intelectual (Cl) limitan las posibilidades del niño para aprender a leer y escribir. La escritura tiene tres fases que de menos a mayor complejidad serian:

- Copia: supone una decuada destreza grafo-motora y perceptual asi como retentiva visual.

- Dictado: es mas compleja porque ya supone haber interiorizado los grafemás, la secuenciación y ordenamiento de los estímulos auditivos que a través dé la representación mental se convierten en lenguaje escrito.

- Espontánea: de mayor complejidad porque no se apoya en las afrencias visuales ni auditivás. Requiere de la existencia de un buen lenguaje interior.

En los niños con bajo cociente intelectual el nivel que se puede llegar a alcanzar es el de la copia, pero el dictado y la escritura espontánea no tienen muchas posibilidades por el proceso de interiorización que involucran. Obviamente todo esto depende del grado de desarrollo de inteligencia.

\section{ETIOLOGÍA DE LAS DISGRAFÍAS}

Además de las causas por transtornos en los requisitos anteriormente mencionados hay un factor que incide notablemente y son los errores educativos que se pueden cometer al ejecutar el proceso de enseñanza-aprendizaje. Según los autores Brueckner y Bond las siguientes son las causas que pueden producir transtornos de escritura desde el punto de vista de fallas pedagógicas:

- Instrucción rígida e inflexible que no tiene en cuenta las diferencias individuales.

- Deficiente orientación del proceso de adquisición de destrezas motoras.

- Establecimiento de objetivos demasiado ambiciosos para las posibilidades de los alumnos.

- Materiales inadecuados para la enseñanza.

- Orientación inadecuada al hacer el cambio de la letra script a la letra cursiva.

- Incapacidad para enseñar a los zurdos la correcta posición del papel.

- Práctica de la escritura como una actividad aislada. 
El bilingüismo no es en sí mismo causa de dificultades de escritura, pero en niños que no están preparados para una educación bilingüe pueden presentarse transtornos en la adquisición de la lectoescritura.

\section{DIAGNÓSTICO DE LA ESCRITURA}

Al hacer una evaluación no se evalua solamente la escritura como tal sino los componentes implicados en su ejecución y los transtornos de simbolización.

1. Escritura: Ajuriaguerra ha creado la llamada "escala de disgrafía" en donde se valoran tres aspectos: la página, la torpeza y los errores de forma y proporciones.

- La página:

Conjunto sucio

Línea rota

Línea fluctuante

Línea descendente

Palabras amontonadas

Espacios/palabras irregulares

Márgenes insuficientes

- La torpeza:

Trazo de mala calidad

Letras retocadas

Desigualdades

Arqueos de m, $\mathrm{n}, \mathrm{u}, \mathrm{i}$

Angulación de los arcos

Puntos de empalme

Encolados

Yuxtaposiciones

Tirones

Finales con impulso

Irregularidades de dimensión

Zonas mal diferenciadas

Letras atrofiadas

- Errores de forma y proporciones:

"Letras muy estrechas o demasiado lábiles 
Malas formas

Escritura muy grande o muy pequeña

Mala proporción de zonas gráficas

Escritura demasiado extendida o estrecha.

1. Componentes implicados en su ejecución:

Se tienen en cuente diversos factores biomecánicos como son:

- Posicionamiento del papel.

- Actitud general de cabeza, hombros y tronco: alteraciones posturales y tónicas.

- Posición del codo y del antebrazo.

- Apoyo de la muñeca.

- Grado de prono-supinación de la mano.

- Oblicuidad con respecto a la línea de escritura.

- Grado de flexión o extensión de la mano.

- Posición de los dedos.

- Flexibilidad/rigidez de la mano.

2. Transtornos de simbolización:

- Omisiones o agregados

- Uniones o separaciones incorrectas

- Transposición o inversión de silabas (tra=tar, la=al)

- Contaminación o paralogismo: escritura de palabras tan deformadas que son totalmente ilegibles.

- Sustitución de fonemas similares auditivamente.

- Sustitución de letras parecidas ( $p=q$ ).

\section{FORMAS DE INTERVENCIÓN DE TERAPIA OCUPACIONAL}

Una vez se ha detectado cual es el origen del problema se pueden generar objetivos específicos de intervención. Algo muy importante es orientar al maestro sobre las causas del transtorno para que las comprenda y logre orientarlas dentro del aula escolar.

En términos generales podriamos hablar de algunas formas de orientar el tratamiento: 
- Ejercicios sensoriales en donde el niño experimente las letras y palabras a través de su sentido visual, auditivo, tactil y cinestésico.

- Ejercicios motores en los que se haga la reproducción de letras y palabras en el aire, con el cuerpo, desplazándose sobre ellas dibujadas en el piso.

- Actividades motoras gruesas que mejoren el control y ajuste postural, reacciones de equilibrio y enderezamiento, tono muscular, coordinación.

- Actividades sensoperceptuales que involucren discriminaciones de formas y tamaños, posición en el espacio, relaciones espaciales, esquema corporal.

- Dentro del enfoque biomecánico se involucran aspectos como tamaño y posición del espacio gráfico, tipo de herramientas a utilizar para escribir, posicionamiento corporal, posicionamiento de la mano con respecto al espacio gráfico y a la herramienta utilizada, tipo de papel (de acuerdo a la resistencia que proporciona), altura de asientos y pupitres, etc.

- Asesorías a maestros y padres de familia para realizar un trabajo en equipo que brinde mayores posibilidades de éxito.

- Comunicación constante con otros miembros del equipo que estén involucrados en el proceso como psicología y fonoaudiología en caso de transtornos psicosociales o de lenguaje respectivamente.

\section{CONCLUSIONES}

El aprendizaje de la escritura es y seguirá siendo pilar fundamental del desempeño académico de los estudiantes. Como terapeutas ocupacionales tenemos una gran responsabilidad en nuestro trabajo en el sector educativo ayudando a descubrir las causas de la disgrafía y a buscar soluciones que le permitan al maestro abordar el problema y al niño superarlo.

Siempre que tengamos a un estudiante con dificultades, debemos involucrar y comprometer tanto a maestros como a padres de familia dentro de la intervención para lograr mejores y mas rápidos resultados. Educando y orientando a estas personas beneficiaremos inmensamente a los niños porque los niveles de tolerancia y de exigencia disminuirán debido a que habrá un mejor entendimiento del problema. Finalmente no debemos olvidar que nuestra labor dentro del sector educativo es primordialmente preventivo. Por lo tanto no debemos esperar solamente a que nos sean remitidos niños para el programa de nivelación sino que debemos estar aten- 
tos a través de nuestras observaciones directas en el aula de indicadores que nos permitan detectar y prevenir futuros transtornos de escritura.

\section{BIBLIOGRAFÍA}

Case-Smith, J. Occupational Therapy for Children, Mosby St. Louis, Third edition.

Jordi,G. Para una pedagogia integral vivenciada. Madrid: Ciencias de la educación preescolar y especial, 1984.

Portellano, J. La disgrafía. Madrid: Ciencias de la educación preescolar y especial, 1985. Ajuriaguerra, J. La escritura del niño. Barcelona: LAIA, 1983.

Zazzo, R. Manual para el examen psicológico del niño. Madrid: Fundamentos, 1971.

Jiménez, J. La prevención de dificultades en el aprendizaje de la lecto-escritura. Madrid: Ciencias de la educación preescolar y especial, 1983.

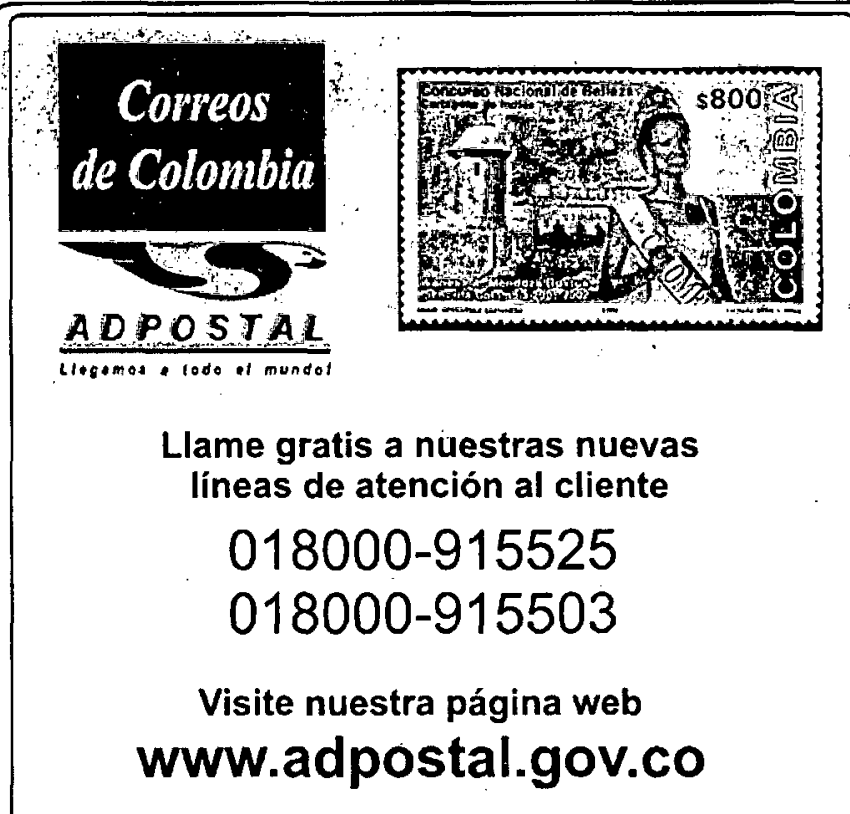

